\title{
Chapter 3 Solutions
}

\begin{abstract}
Universities should develop a system of trust in academic staff to replace managerialism, replace competition with collaboration, and adopt a global perspective to educational inequalities. Three new programmes are proposed. Universities should place education in a framework of environmental sustainability-the Distributed University, moving to online learning which will become the main mode of university education in the future.
\end{abstract}

Keywords Managerialism $\cdot$ Collaboration $\cdot$ Online learning $\cdot$ Environmental sustainability

Building on the identification of problems in the previous chapter, I now turn to solutions. I hope that you will appreciate the progression from problem to solution. I am suggesting that trust replace managerialism, that collaboration replace the competition of commercialisation, that we use online learning as the key educational mode to reflect the way young people learn, that we share educational resources, and that we take a global perspective to educational inequalities. These will all place education in the context of environmental sustainability, using a distributed university structure. I have a number of detailed programmatic suggestions - a higher educational variant of the International Baccalaureate, a 'Global Online Learning' programme, and a 'Plan E for Education' to increase public access to higher education. An ambitious set of suggestions, I know. But we do need ambition and innovation for the university sector to survive and prosper.

\subsection{Develop Trust in Academic Staff to Replace Managerialism}

I described in the section on managerialism how my personal autonomy to administer a large grant was eroded by university managers. Initially I was trusted to administer my own group to meet the requirements of the grant I led, as well as for the other grants received, but this was removed as part of an institutional reorganisation. The section also described how managerialism has interfered with many academic activities 
such as approval of courses and assessments and any university academic today can give many more personal examples where managerialism has added to workload by creating extra internal regulatory requirements, and diminished a sense of academic independence. So the problem is much more than trust in the administration of a grant, but trust in the performance of academic duties. The simple solution I would like to propose is that managers should place more trust in academics, and reduce central control and the heavy administrative burden that it places on staff and the institution.

Of course I am not by any means the first to identify the problem-a quote from one of the papers referenced in the Managerialism section, reports on the results of a large survey of UK academic staff (Erickson 2020) and concludes that it reveals “... an acute situation of endemic bullying and harassment, chronic overwork, high levels of mental health problems, general health and wellbeing problems, and catastrophically high levels of demoralisation and dissatisfaction...is a call to action to demonstrate, and support responses to, the woeful state of management and governance... academics cannot wait for university leaders to rise to a challenge they do not recognise... address this dilemma by developing a different way of thinking about accountability that restores trust and autonomy".

Trust. Dirks and Ferrin (2001) tell us that "Scholars from various time periods and a diversity of disciplines seem to agree that trust is highly beneficial to the functioning of organizations".

Tallant and Donati (2020) use Mayer's definition 'Trust is the willingness to be vulnerable to the actions of another party based on the expectation that the other will perform a particular action important to the trustor, irrespective of the ability to monitor or control that other party', and makes the point that "Trust is a positive expectation regarding the behavior of somebody or something in a situation which entails risk to the trusting party." Das and Teng (2004) emphasise that trust does incur a risk and that there is a relation between trust and risk, with most definitions of trust implying risk.

Trust or control? The nexus between trust and control is complex-they are alternative organisational methods and as Bijlkisma-Frankema and Costa discuss (2005), “...studies support the theoretical idea that trust lubricates relations between partners and organizational processes by promoting a variety of voluntary behaviours that enhance trust-building and performance." and "the higher the level of trust in relationships, the lower the costs of monitoring and other control mechanisms". Given this latter point about cost saving, it is surprising that universities have abandoned trust for control.

This is supported by a popular report relating to the business sector (2019) by Great Place to Work which summarises: "There is a strong connection between a high-trust culture and business success. In fact, the connection is so strong that it can reasonably be argued that strategy-minded leaders, who care deeply about the financial well-being of their business, should make building a high-trust culture a top priority."

There are also suggestions that trust is important in the student teacher relationship (Houldsworth 2020), so an organisation which values trust between managers and 
staff might well find that this extends to improved educational outcomes among students.

The solution is clear-change the structure to increase trust in and independence of the academic staff. But is this warranted? Will there be threats to the quality of the education, research or service provision? Will there be benefits?

What about quality - is trust a risk for the quality of the educational product? On the contrary according to Dzimińska and colleagues (2018) who state that "the intentional development of trust serves the purpose of enhancing the quality culture in higher education."

Of course it works both ways, employees may have lost trust in their managers as well as the other way round. Brower and colleagues (2008) find that "when they trust their subordinates, managers get employees who are more productive, extend help beyond the requirements of their jobs, and remain longer. Consequently, we can conclude that it is in the best interest of managers to trust their subordinates and to behave accordingly." But also, there are mutual benefits when the employees have trust in their managers.

It needs to be said that the findings of a 2019 systematic review of the evidence (Guinot and Chiva 2019) suggests that the evidence of the benefit of 'vertical trust' is patchy.

Niekerk (2016) brings us back to the university sector and argues that "the university during times of supercomplexity should focus on interrelationships between different sectors of the university to re-establish mutual trust relationships."

So, there is a considerable amount of evidence that trust in employees increases productivity and job satisfaction. Why have universities globally reduced the trust in their staff and increased checks and controls? I suspect that this reflects outdated management theory, as well as an inappropriate risk management strategy. There clearly are risks to both the reputation of the institution and to the outcomes of student education and research excellence, if academics do not perform well and provide education of poor quality. There are reports of lazy tutors, researchers who cheat and falsify their results or plagiarise other peoples' work. But is increasing managerial oversight the best way to prevent this? Where are the evaluations that point to increased oversight as a risk management strategy in comparison with increasing the trust placed in the academic staff?

The Covid-19 pandemic has pushed more and more educational activity online. In other parts of this book, a massive scaling up of online education is one of the solutions I am suggesting for the higher education sector. Of relevance in this section is the increased transparency that this offers. All tutor/student interactions can be captured by the online platform software and are available for review. Course materials, discussion forums, examination marks and feedback are all there for the manager to explore in a way that is missing in face-to-face teaching. This has not been fully appreciated by university managers as a way of quality assessment, and requires less intrusion by central control mechanisms.

Another feature of the Covid-19 pandemic is a global and very fast drive to online teaching. This has depended critically on the skills and hard work of the frontline academic staff, with support from IT and educational designers, but the managers are 
much more remote and non-contributory in this process. So this has demonstrated the importance of trusting the academic staff without close managerial oversight.

A change of the power dynamic between academics and managers will introduce risk. It would be important to evaluate whether reducing the power of administrators vis a vis that of academics will lead to better outcomes, and actually facilitate or obstruct the main structural reforms which are required and discussed later.

Of course, it is possible that a reason that managers are not keen to move from managerialism to trust as their underlying strategy is that this would reduce their own relevance and result in job losses among managers. The cost savings for the institution would be considerable, especially if this is associated with a change from the corporatisation model and the high salaries to senior executives that this implies.

Since managerialism and the competitive business model are so intimately connected, a move away from managerialism will open up a number of other possibilities — starting with developing a focus on collaboration.

\subsection{Focus on Collaboration-And a New Taxonomy}

I previously described my experience of, and reservations about, the needless competition between universities for students and reputation. In this section I want to discuss the benefits of collaboration rather than competition. If the higher education sector were to take collaboration seriously, it would provide the potential to redress the mission of universities and tackle many of the problems I have identified. In this and subsequent sections, I outline some practical steps that could be taken by, within, and between universities.

We should start by adding collaboration as an important and measurable educational outcome as an attempt to change the culture within educational organisations. At its simplest level, preparing graduates to work as members of a team would seem to be an important way to ensure that a university education is relevant to the realities of the workplace, where teamwork is a key feature of most industries. If educational programmes within universities have elements of collaboration, this might sow the seeds for wider collaboration within and between universities. There is a great deal of evidence of the power of collaboration, and many excellent examples within the higher education sector, so what I am proposing is not a new concept.

I have been part of a number of research collaborations within and between universities, and one major educational collaboration-the International Clinical Epidemiology Network (INCLEN). INCLEN was a formative experience for me, only partly due to the fact that the grant brought me to live and work Australia. The Rockefeller Foundation funded three (and later four) universities in different countries to provide the educational components of a programme aimed at building capacity in what has come to be termed Evidence Based Medicine. Individuals from 26 universities in Africa, Asia, India and Latin America, from the disciplines of medicine, statistics, health economics and health social science were set up in multidisciplinary units on 
their return from training. The units then performed collaborative research and developed their own educational programmes. From a small start in 1980, INCLEN (www. inclentrust.org) now comprises core functional units in 89 academic institutions in 34 countries.

The INCLEN programme demonstrated collaboration at three levels: between the education providers in three countries, between departments and disciplines within the educational programmes offered by these providers, and between the various academic disciplines in the units once established in the home universities. Although the programme and its results demonstrated to me the power of collaboration, it needed an external agency, the Rockefeller Foundation, to start and maintain itfor 21 years-before it achieved independence. As we consider the evidence for the power of collaboration, we can also think about the drivers and enablers of collaboration - there are not too many Rockefeller Foundations.

Kezar (2005) has documented some of the early research in this area, and I am using the quote to set the scene: “...researchers have documented the benefits of organizational collaboration including greater efficiency, effectiveness, and perhaps most important for higher education institutions, it can enhance student learning. In addition, accreditors, foundations, business and industry and government agencies have been espousing the importance and value of collaboration for knowledge creation and research, for student learning and improved organizational functioning. As a result of both the external pressures and the known benefits, many forms of both internal and external collaboration have begun to emerge nationally. For example, in terms of external collaboration some campuses partner with local businesses to increase their teaching pool and internship potential and provide needed labs and materials for conducting research. An example of internal collaboration is the formation of cross-disciplinary learning communities that bring faculty and students together to study an issue, capitalizing on intellectual capacities throughout the institution for teaching. Similarly, faculty have begun to form multi and interdisciplinary research centers to address the pressing problems of our times and student and academic affairs divisions are working together to deliver joint programs and services."

In this section I go through the various types of collaboration that might be relevant.

1. To start-can we collaborate within an individual university?

You would think that this is easy, and that working with your colleagues towards a common good would be a high priority. There is even a substantial literature about how to collaborate effectively. There are some situations where it is essential for academics to work together, for example when a department wants to design a new course. However, collaboration is not always easy or fully understood by the academics: Newell and Bain (2020) have studied the perceptions of a group of academics engaged in course design about how prepared they were for collaboration. They report that "The existing research also indicates that a complex matrix of personal, professional, social/cognitive and organisational factors are crucial to the effectiveness of team-based collaboration" but that "...participants reported that current conditions at the institutional level serve as inhibitors to collaboration in 
course design. This included the absence of committed leadership and organisational supports for collaboration. Participants described the dominant culture as more supportive of individualised, competitive and hierarchical work practices. Under these work conditions, participants noted a reliance on individuals' goodwill to collaborate in the absence of broader organisational structures and support....they did not express a depth of understanding about the cognitive and social capacities required for collaboration and the skills, structures and processes necessary to enable team-based collaborative practice".

Collaboration in research is vital, as single person research is a rarity today with multiple skill sets required to tackle most problems. There are some rules that will make collaboration more productive, such as agreement in advance on authorship of resulting publications. Collaboration can be within or between departments and faculties, as well as broader as we discuss below.

For collaboration between departments, or faculties within the same university, the same issues apply, although threats to collaboration from competition for resources between departments are even more relevant than within departments.

But how to collaborate-what is needed?

Back to Kezar (2005) who describes a model for how institutions can move towards collaboration "The first stage, building commitment, contains four contextual elements-values, external pressure, learning and networks. Here the institution uses ideas/information from a variety of sources to convince members of the campus of the need to conduct collaborative work. In the second stage, commitment, senior executives demonstrate support and re-examine the mission of the campus and leadership emerges within the network. The third phase is called sustaining and includes the development of structures, networks, and rewards to support the collaborations."

There are a number of software tools to aid collaboration online, highly relevant to today's distributed world.

2. Can different universities collaboration with each other?

Mintz puts the need for collaboration very clearly (2019): "The most striking consequence of institutional competitiveness is the failure of colleges and universities to focus on the needs of the ecosystem as a whole. Many of the most severe challenges facing colleges and universities can't be solved one institution at a time. Whether this involves improving enrollment of low-income and underrepresented students or increasing the number of non-traditional students who receive a meaningful degree, cross-institutional cooperation and collaboration, not competition, is part of the answer...The time has certainly come for a more collaborative higher education ecosystem with far greater sharing than is the case today." $\mathrm{He}$ is calling for us to look at broader national needs for education, rather than just the needs of the individual university. This resonates with some of the points about national and global needs which I make elsewhere in this book.

There may be a number of ways in which funding bodies can promote collaboration between universities. However, there are also some structural barriers to collaboration between universities that could easily be overcome. An example of 
one of these is requirement by funding bodies in Australia to award the majority of the funds to a lead university, which can be a negative incentive.

I am pleased to say that there are some excellent examples of collaboration between universities. One example is the Biostatistics Collaboration of Australia http://www.bca.edu.au/ where six universities have combined to offer a master's programme. The collaboration was established to meet a national and international skills shortage and was the initiative of committed teachers. The programme has been going for many years and has an impressive list of alumni, as well as industry support as many industries need the skills that this programme produces in its graduates.

\section{Can universities collaborate with other organisations?}

My focus and experience has been in the health field, where 'industry' collaboration is fundamental and students are trained for professions in a very clear way. There is clear articulation between the education and the profession into which students graduate. In many countries, student numbers are restricted in order to populate, but not overpopulate, the profession-although predictions of numbers of doctors required are often incorrect and emergency catch-up and recruitment from overseas have been required in the past. Although the assertion that there were more Malawian doctors in Manchester than in Malawi appears to be a myth, the story of how the UK and Australia for example have populated up their own health workforce at the expense of the lower income countries is quite a disgrace. Health professionals emigrate to greener pastures, leaving the countries who trained them with ongoing manpower shortages. This is not, of course, restricted to the health professions.

Leaving aside the difficulties in predicting workforce requirements and the corrections that need to be made, health is one of the particular professions where universities can point to a clear relation between education and workforce needs. The marketplace for students does not in general relate closely to the requirements of the workplace. Universities can claim that a university degree teaches generic skills including how to learn and how to think critically, which will be important for any profession. And global workforce trends are difficult to predict. However, closer collaboration between universities and industry, to discuss needs and appropriate educational outcomes, should lead to less unemployment of graduates and more education that is fit for purpose. The Biostatistics collaboration discussed above is an excellent example. You will see that this is a key component of the distributed university structure that I propose in a later section.

More broadly Mehling and Kolleck (2019) suggest that collaboration across sectors and with practitioners is essential for the sustainability of the university sector. Unless the university sector takes this seriously, it may be left behind by other providers who link learning to industry needs-for example Google career certificates https://grow.google/certificates/.

4. What about international collaboration?

This can be between universities in any setting, and most, where they exist, have involved research collaborations among universities at similar levels of expertise and 
development. The European Union has a very strong record of facilitating research collaborations among European countries and beyond-the goals of its research and innovation policy are 'Open innovation, open science and open to the world are the 3 main policy goals for EU research and innovation.' https://ec.europa.eu/info/res earch-and-innovation/strategy_en Many universities across Europe have been part of research consortia, and have partnered with like-minded universities and research groups across countries.

The 'open to the world' policy is stated to be increasingly important, with one of the EU Commissioners stating: "It is not sufficient to only support collaborative projects; we need to enable partnerships between regions and countries." https://ec. europa.eu/research/iscp/index.cfm?pg=policy.

The EU also has a strategic framework for European cooperation in education and training, which emphasises collaboration between countries within and beyond Europe (https://ec.europa.eu/education/policies/international-cooperation/ international-cooperation-and-policy-dialogue_en). There are many examples of international curricula and joint degrees.

This resonates with the Sustainable Development Goals, where goal 17, titled 'Partnerships for the goals', has the headline goal to 'Strengthen the means of implementation and revitalize the global partnership for sustainable development' (https:// sustainabledevelopment.un.org/sdg17).

Rubin (2017) tells us that "While many large universities collaborate internationally on research, very few have significant experience with intensive collaborative networking in pedagogy (the theory of teaching)" and he reports on an international initiative, COIL, where "teachers from two cultures work together to develop a shared syllabus, emphasising experiential and collaborative student learning."

Joo and colleagues in 'Unlocking the power of collaboration' (2019) promote the value of higher education-focused networks "Oriented around the cross-cutting problems of improving student success and social mobility, enacting structural and cultural change, and managing overlapping organizational responsibilities, these networks develop and strengthen enduring relationships that iteratively generate new ideas and processes to tackle the most pressing postsecondary problems of our times."

The OECD report 'How international collaboration can help build the future of education' (2017) states: "Collaboration is the key to finding solutions on complicated problems, and education is no exception. Through collaboration, people can build the collective intelligence necessary to address the world's complex problems. International collaboration enables countries and decision makers to connect and come together to learn from each other, find common answers and work for the common good."

We will discuss the importance of online education in a later section, but in relation to collaboration, the OECD report (2017) identifies the key role that online learning has to play: "Perhaps the most distinguishing feature of digital technologies is that they not only serve individual learners and educators, but can also build an ecosystem of learning predicated on collaboration. Technology can build communities of learners that make learning more collaborative, thereby enhancing 
goal orientation, motivation, persistence and the development of effective learning strategies".

5. If we need it, we'd better teach it and add collaboration as a core educational outcome

There is a strong literature about the benefits of collaborative learning, although I am not aware of any evidence for the carry-over of learning collaboratively to professional practice. There would seem to be a logic to hoping for both this carry-over, as well as the idea that if collaboration is a highly regarded educational outcome, the organisation that provides the education would be stimulated to practice collaboration in the way it organises itself.

Scager and colleagues tell us (2016) that "Several decades of empirical research have demonstrated the positive relationship between collaborative learning and student achievement, effort, persistence, and motivation. Collaborative learning potentially promotes deep learning, in which students engage in high-quality social interaction, such as discussing contradictory information."

Laal and Ghodsi (2012) define collaborative learning as "an educational approach to teaching and learning that involves groups of learners working together to solve a problem, complete a task, or create a product" and "sets out major benefits of collaborative learning into four categories of; social, psychological, academic, and assessment benefits."

If we are to teach collaboration, there need to be appropriate educational outcomes identified. Bloom's taxonomy has been in use for many years to help us define the outcomes we might expect at various levels of learning. Bloom devised his taxonomy of learning in 1956 and it was revised in 2001. In the pyramidal hierarchy, the 2001 version starts with 'remembering' and rises to 'creating' as the highest order skill. This classification has been very important in defining expected educational outcomes. For example, master's degrees might extend to the 'Analyse' and 'Evaluate' levels, and PhDs to 'Create' - the highest level.

Collaboration does not appear in either version, although a further revision to a 'digital taxonomy' did add collaboration as a separate element (Churches 2008). My suggestion is to add collaboration as a key component-and I have called this next version the 'New Bloom', as in the picture which shows each of the versions. I've put 'Collaborate' between 'Apply' and 'Analyse' — so it is a quite high level skill which will be needed at each of the levels above it (Fig. 3.1).

Building on the theme of collaboration and reduction in competition, the next section makes a suggestion for a university version of the International Baccalaureate which has been adopted in the secondary education (high school) sector. 

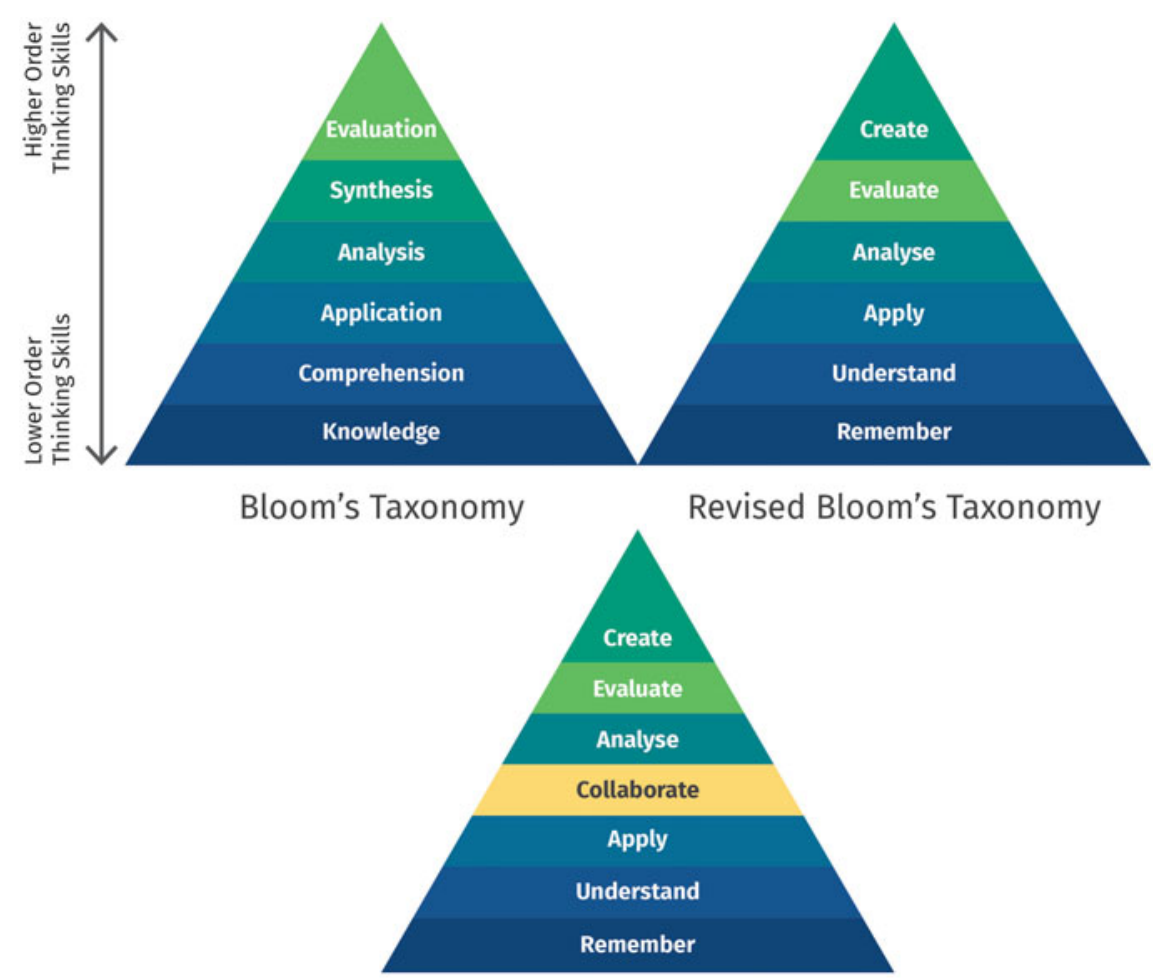

New Bloom

Fig. 3.1 The 'New Bloom' taxonomy includes collaborate

\subsection{A Proposal for an 'International Baccalaureate' for Higher Education}

Why does each university feel that they need to develop their own course? Why waste so much time, effort and resource? To reduce redundant duplication of the development of teaching programmes and competition between universities, I would like to suggest the creation of a higher education version of the International Baccalaureate used in schools. This would involve a global collaboration between universities that would reduce competition and standardise quality. Such an 'International baccalaureate' for higher education could be called the 'International Degree Programme' or 'International Tertiaire'.

An example from my personal experience is the Peoples-uni which offered online master's courses in Public Health for more than a decade, and to which I refer frequently. The course content is published under a Creative Commons licence, which means that anyone can use it provided they give appropriate attribution. The course has been designed and taught by an international faculty of academic and service 
volunteers who have considerable experience and expertise, and the programme has been reviewed favourably by an external evaluation. We have tried to offer the programme to universities who do not have such a course across a number of continents and countries-but without much success. Why does each institution feel the need to develop their own when you can have one ready made?

Although primary and secondary schools usually teach to a common curriculum, mandated by state or national bodies, universities have authority devolved to them to design and approve their own degrees within a general quality approval framework. In addition, there is a second framework that exists for some professional degrees which require national or international accreditation, to hold universities to account in those areas. There are attempts to standardise curricula, such as the European Bologna process (https://www.eua.eu/issues/10:bologna-process.html) which offers standards - what type of structure and length of study might you have in undergraduate or master's degrees for example. However, each university feels the need to develop their own degrees, partly to have some competitive advantage over other providers.

One of the major resource constraints of the higher education sector is the time and effort required to develop and 'manage' the curriculum and assessments. This not only uses academic time, but is used to self-justify the existence of a class of managers to oversee and provide quality assurance.

My suggestion is to offer, to those universities who want it, a standardised curriculum and course content. An extension could also offer the core educational process in addition to the content-the use of online learning could provide a common set of instructions, resources and feedback. The local university can add its own flavour in many ways, including the facilitation of discussions, timetable, input of local experiences, research supervision, and additional assessments. Most of the development and approval work, resources and managerial oversight can be 'outsourced' to an organising body. This would be another way in which savings could be made in managerial staff, academic time could be saved, common quality assured, and local expertise and variation accommodated.

The International Baccalaureate offers a potential model at the schools level, on which the Higher Education version could build. A common curriculum is offered, as well as a number of resources and offers of professional development for teachers. It mission statement (https://www.ibo.org/about-the-ib/) is:

- The International Baccalaureate aims to develop inquiring, knowledgeable and caring young people who help to create a better and more peaceful world through intercultural understanding and respect.

- To this end the organization works with schools, governments and international organizations to develop challenging programmes of international education and rigorous assessment.

- These programmes encourage students across the world to become active, compassionate and lifelong learners who understand that other people, with their differences, can also be right. 
The term Baccalaureate actually means a bachelor's degree, the first level in higher education. So we would need a new term, such as 'International Tertiaire' (French for tertiary) or 'International Degree Programme', as well as some modifications of the International Baccalaureate structure to make it fit for higher education. I would hope that a philanthropic organisation might kick start it, but I think it would be sustainable through a small administration fee from participating universities in the manner of the International Baccalaureate. Since resources would be freely available to all, as described below, any participating university would be paying only for the accreditation and badging of their degree as part of the 'International Tertiaire'. This would imply a light touch online quality assurance process from the organisation to each participating university. The simplest mechanism would be an external examiner system with examiners from among the participating universities, and as a peer to peer assessment would provide benefit to both the examiner's home institution as well as the one under their external review. The whole programme could be mainly self-organised with groups of universities coming together around discipline groups. Of course an evaluation process should be built in from the start, and again this should be performed by the academics of participating universities with publication being the reward.

This idea would resonate with a number of the sections in this book-it would reduce unnecessary competition between universities, reduce opportunities for managerialism, enhance international collaboration and the internationalisation of education. The external examination and self-organisation into groups of universities each speak to the importance of inculcating trust, which is central to my suggestion to replace managerialism. All administrative and resource functions would be carried out online, and to resonate with the Plan E for education (in a later section of this book) with the curricula and resources being open source and becoming Open Educational Resources.

Once a philanthropic, or other, organisation has taken the bait to kick start this idea, various of the details will need to be discussed and revised before such a process would be piloted, evaluated, and subsequently introduced into practice.

Although the next section does not flow easily from the previous discussions on collaboration, it makes a suggestion to expand the current use of volunteer educators. This is not going to be a fundamental solution to the problems facing universities, but is generally ignored and can play a part to the benefit of volunteers, universities and students.

\subsection{Utilise Volunteers as Untapped Educators}

As a medical student, I learned the skills of clinical medicine from the doctors who were employed by the hospital rather than by the university. In those days, being on the staff of a teaching hospital was a marker of status-and probably allowed the doctors to charge higher fees in larger private practices—but the university did not have to pay the salaries. With some variation, this pattern for clinical skills teaching 
provided by the profession, at least in addition to university paid staff, has continued and is seen globally. Most university courses that prepare students for any profession rely on similar expertise and commitment. It is vital that professionals help in the education of students destined for that profession so that the relevant skills can be learned.

Volunteerism is a part of many educational activities. Volunteer teachers work in schools and various professions offer work experience for schoolchildren. The Children's University Worldwide encourages people in the community to offer extracurricular experience to children so that their education is broader than just that which they can gain at school. Many universities have volunteer programmes to add to the courses offered, such as language and acculturation programmes for students from overseas. Many countries encourage volunteer teaching in international settings - to the benefit of both the host country and the volunteers who go there and gain experience and satisfaction. The Granny Cloud http://thegrannycloud.org/ has volunteer "native English speakers Skype in with children in these remote and disadvantaged locations and enable them to pick up English in the way we typically pick up any language - through hearing it spoken around us and using it in conversation" The role of the 'Granny' is through online discussions "providing praise and support to enable the children to work as a community and take the lead in their learning, helping them to explore and develop their natural curiosity".

My experience with Peoples-uni (http://peoples-uni.org) gives me the confidence to suggest that there is a great scope for increasing a role for volunteers in education. Peoples-uni relied on volunteers to provide all the educational tutoring and assessment activities in a master's level online capacity building programme. Over 14 years, more than 400 Public Health professionals, both on the academic and service sides, acted as tutors for students who are themselves health professionals and working in developing countries. There was a regular enrolment of volunteers, either having found the programme themselves or having been invited by a current volunteer. In any partnership, both partners need to gain something. So if volunteers provide a service, they need something back. Our Peoples-uni tutors gained personal satisfaction from helping others obtain skills which they can use for professional development and to help improve the health of their populations. But the tutors also gain practical benefits - they may be able to claim credit for this experience towards their own continuing professional development programme, they may learn both from the course materials and from the students about global health problems in different settings, they may learn about modern educational methods and information and communication technology, and they may be able to develop links and collaborations with other tutors and students for collaborative research. The benefits of collaboration, which we have previously discussed, maybe gained for use in the professional and personal lives of the volunteers. In a survey of Peoples-uni volunteers, "The majority (75\%) were keen to continue in their role for the foreseeable future and $71 \%$ felt very well looked after by their module leaders and colleagues. Responses highlighted that volunteers embraced the mission and characteristics of Peoples-uni." (Heller et al. 2019a). 
For professionals who work in a service setting, exposure as educators in a formal educational environment has extra appeal as a way of adding a dimension to their professional lives. This is the group which I suggest should be tapped in a more systematic way in the new sustainable higher educational future which I am postulating.

Volunteering is widespread, with rates of volunteering varying from 17 to $38 \%$ in different continents, although there are large variations between countries. There are socio-economic variations in rates of volunteering. Volunteers contribute the equivalent of many billions of dollars in employee wages. There is a scientific literature about volunteering, including a trend towards episodic volunteering rather than a constant commitment (Hyde et al. 2014; Southby et al. 2019) and there is evidence that volunteering may benefit mental health and survival (Jenkinson et al. 2013). Academics are used to volunteering their time as peer reviewers of journal articles and research grant applications.

Motivation to volunteer might be either altruism or self-interest (Nichols et al. 2019), although ideally it will be a mixture of the two. Doing something for others, while gaining benefit yourself, is a potent mix. The Peoples-uni experience shows that this can be achieved in an education programme-although we would not expect other educational organisations to be as fully dependent on volunteers.

So, there are many precedents and reasons for volunteers to contribute to education. We are missing many opportunities to capitalise on this and I suggest that our university of the future creates a systematic approach to the use of volunteers as teachers and support persons. As you see, this university of the future is online, enabling volunteer engagement irrespective of geography. There will have to be appropriate governance, including initiation and guidance, backup and the issuance of volunteer certification.

Here is how it may work. Both individual or institutional volunteering, where an industry offers its employees the opportunity, are encouraged. The university has a special volunteer section, with various support options for volunteers. These would include a centralised certification facility which departments can use to provide certificates for volunteers to recognise their service, resources to help volunteer teachers and support staff in their role especially on initiation, and news and forums to encourage a feeling of engagement with the institution. Volunteer options would be advertised and would include any and all of the functions of the university at all levels including leadership roles. The volunteer section should be staffed by those who understand the science of volunteering and who are prepared to contribute to it through evaluations which may be sent for publication. It would be important to automate most of the support functions and not turn the enterprise into another example of managerialism!

The next sections focus on the central importance I am placing on the use of online learning. It offers at least a partial solution to a number of the problems previously identified. 


\subsection{Move to Online Learning}

Distance education has a long history, and the development of the internet has allowed this remote learning to move online. My first experience of developing a distance component was with INCLEN which I have mentioned previously. We found that some students who came to one of the training centres in Australia, Canada or the USA managed to find a way to remain and not return to their home countries. This reduced the impact of the programme which aimed to build local institutional capacity in developing countries. Creating a distance version of our course, where we sent materials by mail and visited for some tutorial activity, allowed us to continue to offer the education. We found we could scale up using this method to include more students as well as not depleting local manpower either during the course-or afterwards. We were able to transform the course to an online version as the internet became more available. My move to the University of Manchester allowed me to start a brand new fully online master's programme, and then to develop Peoples-uni on my retirement. My experience has made me increasingly enamoured by the concept and practice of online education.

My proposal is that the main mode of university education in the future will be through online learning. It will not preclude face-to-face experiences, and there are some things which can only be taught in person-learning brain surgery at a distance may not be sensible (although Virtual Reality and other IT developments may surprise us all in the future as technologic educational options). The question always asked is whether online learning is as good as face-to-face. My colleagues and I reviewed the literature (Heller et al. 2019b) and found that online learning was no worse than face-to-face, even better in some reports. This is consistent with other reviews (Cook et al. 2008) and (U.S. Department of Education 2009). The online format also has many educational advantages, such as the ability to encourage self-directed and active learning — and it does away with lectures! Actually, this is important-you cannot just put your lectures online and call it online learning, which requires its own specialised methodology. Online learning also allows a number of the other initiatives I canvass, such as increasing environmental sustainability and the ability to collaborate across universities and geographies. In the chapter on the case study of Peoples-uni, you will see that our fully online programme allowed us to have tutors from more than 50 countries to bring their expertise to the students. The future developments associated with the digital transformation of society, will only expand the opportunities and methods for the provision of online education. As the KPMG report The Future of Higher Education in a disruptive world (2020) states "Spurred by the pandemic, but probably coming anyway, is the reverse situation. Courses will be designed to be delivered through technology_-digital first'-and supplemented by face-to-face, human support."

The negative aspects of online education should not be dismissed. Many learners miss the social aspect of people meeting face-to-face and having para-discussions. There have been concerns expressed about the impact of the social isolation associated with online learning on mental health. However, it is easy to create an online 
community, and some people may actually find this better than the face-to-face experience. Adding the use of technology for education to all the other reasons that people go online could lead to fatigue associated with overuse, reduction in opportunities for exercise and other potential health effects. I am finding it difficult to obtain more than anecdotal evidence for most of this, but there are concerns. Again, these can be addressed through awareness and the design of methods to identify and mitigate potential overuse.

In addition, it is important to confront the issue of cheating, or plagiarism, in online education. There are conflicting reports of the prevalence of plagiarism at the university level - and whether much of this is actually cheating rather than a lack of understanding of how to quote and cite references (Kier 2019). There are a number of studies which find no difference in cheating between online and face-to-face teaching, as summarised by Pilgrim and Scanlon (2018). There are also excellent online software and other solutions that can detect whether something has been copied and pasted from somewhere else on the internet or by another student- these can also be used as an educational tool to help students avoid accidental plagiarism. There are also software tools to 'proctor' examinations to check that the right person is taking the examination online. Better than this, it is possible to tailor assessments in a way that requires students to report personal or contextual experiences that cannot be produced by someone else. These can be particularly useful at the higher end of Bloom's taxonomy of learning, and can incorporate the collaboration aspects which I have suggested be included in the New Bloom taxonomy. My personal view is that cheating actually cheats the students themselves - they end up without the skills and knowledge that they enrolled to gain. However, I do accept that education for a profession, whether this is online or face-to-face, does create an imperative to ensure appropriate knowledge and skills on graduation.

As discussed in a previous section, young people use the online space for so many of their activities, including learning both informally and at school. Failure to fully realise this in an educational context is misguided in the extreme, and misses a wonderful opportunity.

The next sections give more details on how to capitalise on this opportunity and make online learning central to university education, starting with a structure that will enhance environmental sustainability.

\subsection{Place Education in a Framework of Environmental Sustainability—The Distributed University}

As described in the 'Problems' chapter, there already are efforts to encourage environmental sustainability in higher education. These revolve around making university campuses more environmentally responsible, and educating students about the issues. There are an increasing number of initiatives to nudge universities in this 
direction, such as the student led People and Planet who have ranked UK universities according to their environmental and ethical performance (https://peopleandpla net.org/university-league). They use 14 indicators, from carbon reduction to ethical investment and banking. There are other lists of indicators, and toolkits to help universities make the transition-such as the Greening Universities Toolkit from the United Nations Environment Programme (https://www.unenvironment.org/res ources/toolkits-manuals-and-guides/greening-universities-toolkit-v20). Others have their own lists of indicators, such as these five indicators: Energy (electrical and thermal energy); Water; Transport; Waste; Behaviour and management (Freidenfelds et al. 2018).

Many universities have excellent courses in environmental sciences including climate change, and some universities include climate change and environmental sustainability in each of their courses. These will raise awareness as well as developing leadership in tackling threats to sustainability.

However laudable each of these initiatives might be, all of these might be considered rather as tinkering than restructuring. If we are really serious about reducing emissions, universities will have to make much more drastic changes. Despite the global harm caused by the Covid-19 pandemic, the experience has pointed the way to such a restructuring. Students all over the world have found that they can learn perfectly well online. Tutors have found that they can offer rewarding educational experiences from their own homes. A serious pivot from face-to-face to online learning will reduce the impact on the environment from transport and through smaller campuses with fewer buildings. This is also consistent with a number of the other suggestions for change I am making in other sections, such as reflecting the way young people learn. The pivot to online education will also enable the transition from managerialism towards trust in academics as more direct responsibility flows away from central management.

Online learning needs little physical plant—so as we create the 'Distributed University' it will have a very different physical structure. The diagram demonstrates this new structure-and reflects three main components-teaching/research, administration, and the inputs from community, industry and national and global educational needs.

Physical action centres around local learning hubs where face-to-face opportunities can be provided. Teaching and research are provided through these local learning hubs which are distributed across geography and time, and are linked remotely to a central administration focus. Local networks of students around these local learning hubs would create self-directed and collaborative learning experiences, and include tutor support. They may have some physical space requirements for offices, face-toface teaching or research labs, but where appropriate they might be virtual hubs with no physical plant. They should not become smaller versions of the central administrative focus. Some of the physical space requirements might be provided by local industry or community partners, who will also feed into local strategic development and provide educational experiences where appropriate for education for professions, and offer the opportunity for practice based education. 
University administrations have reported a demand from students to resume the face-to-face contact from which they were deprived during the Covid-19 pandemic. This is understandable and probably largely reflects the social rather than the academic attractions of the university experience. Engagement by students with the local hubs proposed here will allow face-to-face contact as well as encouraging engagement with industry and community groups and practice based learning. A sense of belonging to a university community does not need face-to-face contact, and can be achieved though online activities including social media.

Local hubs will also provide the opportunity to engage with other educational providers, such as vocational and technical institutions. This will broaden the ability of the university to respect and respond to community needs, and may be easier to navigate at the local than regional or national levels.

All of these hubs would be supported by a central resource, housing central administrative functions and venues for occasional larger face-to-face meetings for staff and students. The central resource would be physically much smaller than the current university campus, using far fewer resources, and the reduction in managerialism would also lead to re-distribution of central administrative staff. Much of the central activity can be undertaken from home, as can many of the activities in other parts of this networked university. IT support and library facilities will themselves be online, and videoconferencing and online educational development teams would be critical educational infrastructure. This distributed structure will also facilitate educational networks between different universities nationally and globally (Fig. 3.2).

Relationships between the sections in the top half of the picture can be replicated in various local/global settings, and over time.

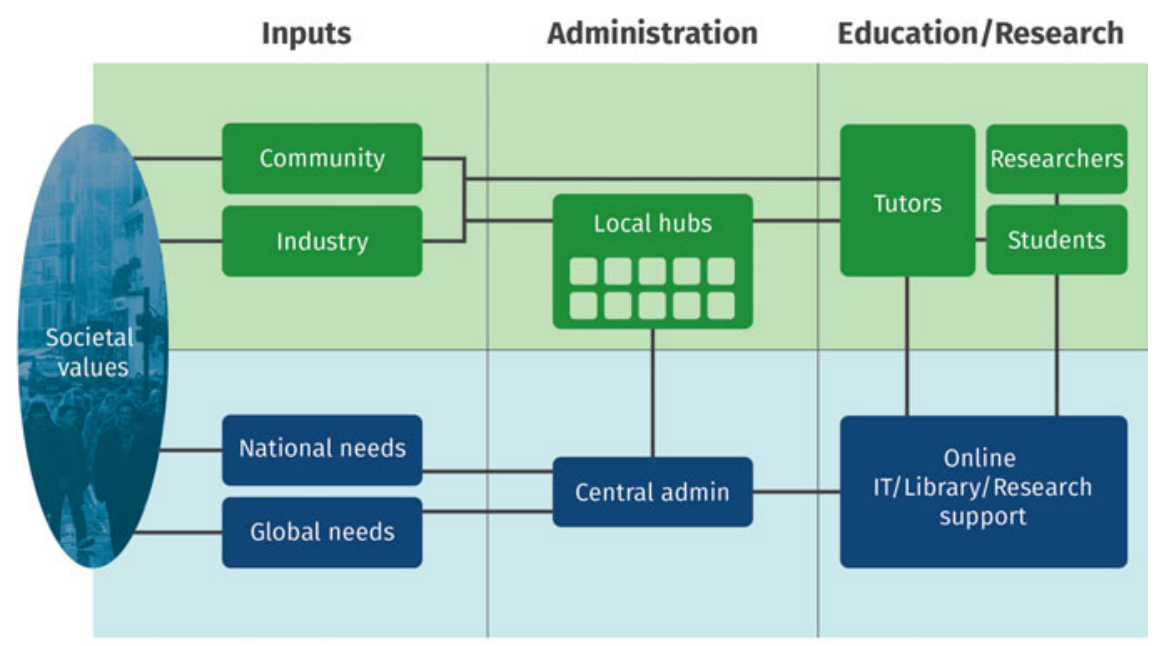

The Distributed University

Fig. 3.2 The Distributed University 
Online library and IT support, including educational design, are going to be key to the future functioning of universities. A grouping of these functions, which may or may not include a physical presence and which would also include research infrastructure, will support each of the local hubs and their students, teachers and researchers.

This model of the distributed university applies to place, as in the above diagram, and to time. The old model of university education taking place in the few years after leaving school has to be replaced by a system of learning appropriate to needs. There are learning needs at various stages of life, requiring lifelong learning.

This resonates with Alexander and Manolchev (2020) who envisage the university of the future "combining high-levels of responsiveness (e.g. a digitally enabled model)... is the Interactive university" or even a "Platform university model...able to connect stakeholders in the process of life-long learning, mediating and participating in the co-creation of multi-disciplinary knowledge, as well as adapting to and catalysing change".

The term Distributed University has been used previously, by Haymes in a perceptive blog (2018) where he states "The needs of knowledge creation have outstripped the physical and organizational infrastructures of universities (and, by extension, the business specializations that they have in turn created) more than ever before...We hope to create a professional organization with no physical "center" to leverage the connective tissue of the internet and united through a federative structure of ideas and principles." There is also a World Distributed University (https://www.newpor tuniversity.eu/global-education-system/wdu/), although this mainly refers to a set of traditional university campuses across different geographical settings.

Stanford University has described the potential for the Open Loop University where students loop back to the university as their educational needs vary over time and they can learn what is applicable to them at a particular stage of their career (http:// www.stanford2025.com/open-loop-university). Rather than 4 years after leaving school, they envisage 6 years over a lifetime. In the model of the Distributed University, these various components can be taken from different geographical settings, as well as at different times in the individual's life cycle.

Let me give a further theoretical approach to how learning needs will change over a lifetime, from the context of Public Health education. Colleagues and I (Madhok et al. 2018) have created the idea of a learning ladder where learning is a continuous process with different requirements at different stages of their careers (and of course afterwards) (Fig. 3.3).

The Learning Ladder describes how health professionals might progress through a career-their educational requirements will change as they progress. There are also, of course, learning needs that are not professionally related, to improve general literacy, knowledge and skills in many areas of leisure activity or to fit people to change career. With the projected increase in artificial intelligence and the reduction in jobs that this might replace, universities are in a great position to offer lifelong learning for these purposes. There is a need, once students have graduated, for continuing education to put theory into practice - distributing education over time as part of the new university structure I have proposed will fit in well if the university will take 


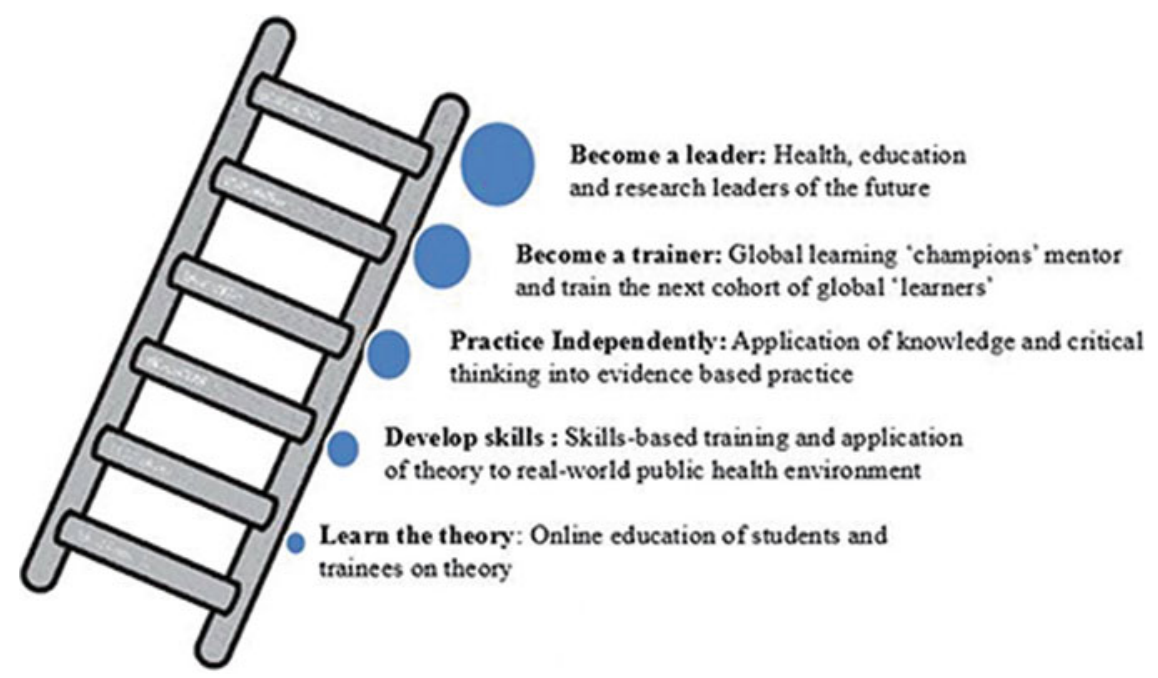

Fig. 3.3 The learning ladder

the opportunity to extend its responsibility in this way. There are other themes to this learning ladder, such as the sharing of experiences between low- and high-income countries in a global context - and we pick up this theme of global learning in a later section.

Central to the use of online learning will be the advantages that can come from using high quality educational resources that have been developed by others, and that are freely shared globally as Open Educational Resources.

\subsection{Use Open Educational Resources}

Open Educational Resources (OER) are 'teaching, learning or research materials that are in the public domain or released with intellectual property licenses that facilitate the free use, adaptation and distribution of resources' (https://en.unesco. org/themes/ict-education/oer). The concept is logical and exciting-educators who develop resources share them with other educators - and in turn gain the reciprocal benefit of resources prepared by others. This avoids duplication of effort and has the potential for globally best practice resources to be utilised.

The idea has been extended to the term Open Educational Practices (OEP) which are the open context or environment in which the Open Educational Resources (OER) are used (Encyclopedia of Educational Philosophy and Theory 2020). OEPs ask how are OER best used in educational theory and practice, whether there is a mechanism for sharing and repositories where a teacher can go to access the resources, as well as whether universities have policies that allow or encourage the use of OER and if there are global agreements to facilitate the development and sharing of OER. 
This educational openness has arisen from the more general 'open source' movement which started with the sharing of code by software developers to improve and speed up the creation of computing solutions (https://opensource.com/resour ces/what-open-source). Each developer can build on the solutions proposed by the previous one, and their collective skills are more likely to achieve a useful outcome than can be achieved by any one individual. This movement, now much more broad than just for computer software, encourages collaboration and exchange of ideas and has the underlying notion of working together to meet a need rather than competition between the players to get there first. So you can see how this fits in with so many of the themes I have been trying to articulate in this book.

Open publishing of research findings has a similar notion, but is aimed at the user of the product, rather than the developer, although both may actually benefit. This is especially relevant for scientific publication. Why should scientific knowledge, especially if it has been created using public funding, be hidden from the readers who might benefit from it unless they can pay? The publishers say that someone needs to provide the funds required for the act of publishing, and of course this is true, but why should this involve profits for the publisher or their shareholders? An alternative way of meeting the costs of publishing is to ask the author to pay, and this is now a common form of scientific publication. A researcher will include publication costs of any journal article resulting from the research in a grant application, and pay the journal's publication fee. In return the article is published under a copyright license that allows free (online) access to any reader. Many government and other grant giving bodies now require that the publications from the research are in open access journals. Each of the research papers that we published about Peoples-uni was in an open access journal as a matter of principle-which is why as the author of this book I am paying the publisher's costs so that it can be freely available to anyone who wants to read it.

There are downsides to open publication of research. Two that have affected me personally are that research which is not funded by a grant requires the publication fees to be found elsewhere-difficult if your university department or the institution where you work is not well funded and even more difficult if you are retired! Of greater concern is the rise of predatory publishers. They make a profit by making a charge to unsuspecting researchers, and do publish the research in their online journal, but do not go through an appropriate peer review process. There is a lovely example (described by the author, Dan Baldassarre, on Twitter) of a journal article submitted as a sting, titled 'What's the deal with birds?' It was published less than a week after being submitted in a journal called Scientific Journal of Research and Reviews. The paper abstract (summary) was: "Many people wonder: what's the deal with birds? This is a common query. Birds are pretty weird. I mean, they have feathers. WTF? Most other animals don't have feathers. To investigate this issue, I looked at some birds. I looked at a woodpecker, a parrot, and a penguin. They were all pretty weird! In conclusion, we may never know the deal with birds, but further study is warranted." In the acknowledgement section the authors said "We thank Big Bird from Sesame Street for comments on the manuscript. Several trained monkeys 
transcribed videos." The processing fees to authors by this journal vary from $\$ 649$ to $\$ 1780$, depending on the country of the author and the type of research article.

This journal and its publishers appear on various lists of bogus publishers, and researchers are advised to check these lists before deciding to submit to a journal. I personally had a recent experience of a different predatory journal where the chair of the Board of Editors was a respected academic with whom I had worked and published in the past. My co-authors and I submitted a paper for publication to the journal. Suspicions during the process were confirmed when we found the journal on a list of potential predatory publishers so we withdrew the paper-to be subsequently bombarded with requests for processing fees (which we did not pay). This attempt to charge withdrawal fees is common practice-as is the appointment of reputable people to the editorial boards who agree without appreciating the predatory nature of the journals. It is difficult to pick these predatory journals-my experience happened after a career which included the publication of around 400 papers in the peer reviewed scientific literature. In the end, the article in question was published in a highly respected journal, with an open review process.

Back to the topic of Open Educational Resources. There is evidence that the use of OER reduces student costs-mainly through access to free textbooks. There are also claims that OER improve learning outcomes (through access to these globally high quality resources). Most research studies of this actually find no difference in learning outcomes, but there are technical issues which might hide any demonstration of benefit (Grimaldi et al. 2019).

There is a great deal of international support for increasing the use of OER, with UNESCO taking a leading role. As recently as 2019, 193 countries voted to pass a UNESCO resolution (https://en.unesco.org/news/unesco-recommendationopen-educational-resources-oer). There are 5 action areas, which include international collaboration. A US based philanthropic organisation, the Hewlett Foundation was also instrumental in supporting OER developments, and there are a number of national initiatives such as OER Africa to push the notion. There is also an OER University $(\mathrm{OERu})$ which offers free and open courses created by partner universities. In practice, however, there is not all that much take-up by universities. Peoples-uni developed a full master's programme with 18 modules, as well as a number of Open Online Courses for continuing professional development, using Open Education Resources and being made available to others through Creative Commons licences. In that way, we could select the best resources available internationally to use in our courses.

Nascimbeni and colleagues argue (2020) "...that the use of OER can have an potential transformational impact on the way universities collaborate and work in increasingly complex and international contexts, mainly thanks to the collaborative knowledge building and the stakeholders' engagement dynamics that the use of OER can foster." Despite the benefits, OER have not been adopted in any large measure by the academic community. Annand and Jensen told us in 2017 (2017) that "OER are still not widely used, and progress toward large-scale adoption in most colleges and universities has been slow". 
I think that the main reason is that the concept is not compatible with the competitive underpinning of the current university business model. This competitive model has also been adopted by the academics themselves who feel they can design better material than anyone else! If universities are to become less competitive and adjust to the new realities of reduced funding and increasing adoption of online education, they do need to get serious about creating and using Open Educational Resources, and researching their appropriate place in education practice.

Online learning and Open Educational Resources take advantage of current communications technology, but looking to the future there are going to be a number of advances that will enhance the ability to transmit education between teachers and students. Some of these are discussed in the next section relating to the fourth industrial revolution.

\subsection{Take Advantage of Modern Technology and the Fourth Industrial Revolution}

I remember being appointed as a senior lecturer in the University of London, and finding that I had an office, with a full-time secretary at her own desk sitting outside my door. The secretary of course typed all my letters, and other duties included typing lecture notes and research articles. In an earlier job, a secretary typed up my doctoral thesis for me. Telling this to today's academic raises a laugh, as all these activities are now performed by academics themselves. While part of the reason to abandon such assistance to academics is financial, part of it is that the technology revolution that allows us to use computers, smartphones and other aids ourselves for these tasks. The use of computers characterised the third industrial revolution (the first industrial revolution was based on the discovery of steam and the second on electricity). The phases of the industrial revolutions have not mirrored the university generations which I discussed in the first chapter to any great extent, and today's third generation universities lag behind the third industrial, digital, revolution.

In a few years time, we will look back on the way we work now in amazement. There is another technology revolution occurring, the 'fourth industrial revolution' (4IR) which will change working and living practice, and the university sector will not be immune. Penprase (2018) describes the fourth industrial revolution as "the result of an integration and compounding effects of multiple "exponential technologies," such as artificial intelligence (AI), biotechnologies and nanomaterials." and suggests that "More than ever, higher education in the 4IR age must develop the capacity not just for analyzing and breaking a technical or scientific problem into its constituent parts, but also must emphasize the interconnections between each scientific problem across global scales and interrelations between physical, chemical, biological and economic dimensions of a problem. The hallmark of the 4IR is exponential growth and rapid change, which gives the curriculum an imperative to update content on 
an unprecedented frequency to match the rapid tempo of scientific and technological advances."

Barnett also warns us in 'Learning for an unknown future' (2012) that the supercomplexity facing us in the future will have its own educational requirements that will need to be considered by universities.

I like this quote from the World Economic Forum website: "The Fourth Industrial Revolution represents a fundamental change in the way we live, work and relate to one another. It is a new chapter in human development, enabled by extraordinary technology advances commensurate with those of the first, second and third industrial revolutions. These advances are merging the physical, digital and biological worlds in ways that create both huge promise and potential peril. The speed, breadth and depth of this revolution is forcing us to rethink how countries develop, how organisations create value and even what it means to be human. The Fourth Industrial Revolution is about more than just technology-driven change; it is an opportunity to help everyone, including leaders, policy-makers and people from all income groups and nations, to harness converging technologies in order to create an inclusive, human-centred future. The real opportunity is to look beyond technology, and find ways to give the greatest number of people the ability to positively impact their families, organisations and communities." (https://www.weforum.org/focus/ fourth-industrial-revolution).

The challenges of the fourth industrial revolution will require rapid change to be incorporated into educational programmes. Online education is going to be key to allow this to happen — and will in itself benefit from the associated technology such as AI. A new academic journal was founded in 2020, Computers \& Education: Artificial Intelligence (https://www.journals.elsevier.com/computers-and-education-artificialintelligence/) to report on explorations of the potential for AI to impact on education. We are going to have to make sure that AI can benefit the educational enterprise-for example in automating some processes to allow us to scale up in reach and numbersrather than allow corporations to use captured big data for their own purposes to target advertising.

If universities are not able to respond to the challenge to help understand and harness these rapid developments, they will become increasingly remote from the needs of the population. Academics will be required to respond to and integrate the components of this industrial revolution, but currently are taken up with administrative duties that limit the time they can spend on these innovations.

Harnessing each of the themes discussed up to this point brings us to a key issue of special interest to me, that of developing a global perspective to educational needs. Next, I make some general points, and then make proposals for two new programmes-'Global Online Learning' and 'Plan E for Education'. 


\subsection{Develop a True Global Perspective to Reduce Global Inequalities in Access to, and Benefits of, Higher Education}

While it is the responsibility of each nation to build its capacity of educated graduates, we have seen that there are gross global inequalities in access to higher education. Of course these cannot be tackled just by a focus on universities, as you have to be a school graduate in the first place to enter university and there are major inequities at this level as well. The Education Commission, a global initiative chaired by Gordon Brown, previously UK Prime Minister, and including various leaders in the fields of education, business, economics, development, health, and security, puts it well "Education and skills are essential for the realization of individual potential, national economic growth, social development and the fostering of global citizenship. In the coming decades, as technology, demographic change and globalization reshape the world we live in, they will become ever more important." (https://report. educationcommission.org/report/) The Commission feels that overcoming inequalities between countries is possible and calls for "a Financing Compact between developing countries and the international community, realized through four education transformations - in performance, innovation, inclusion and finance."

The suggestions I have are not as fundamental as those by the Education Commission, and only apply to universities, but in these next two sections I attempt to offer a way forward. Both suggestions that follow depend on online learning.

\subsection{Reduce Reliance on Overseas Student Fees and Develop the 'Global Online Learning' Programme}

Prior to the Covid-19 pandemic, there were warnings about the dangers of over reliance on income from overseas students. The KPMG report 'The future of higher education in a disruptive world' (KPMG 2020) stated: "Those universities in low fertility rate jurisdictions which have hitched their business model to international students will urgently need to re-visit their strategy and reduce their costs". The Covid-19 pandemic exposed that in many countries the university sector was vulnerable to the financial risks from over-reliance on income from overseas students. At the time of writing, a number of Australian universities are facing bankruptcy and possible campus closure, and most are facing staff redundancies as the cash cow from overseas student fees dries up. The problem of this over reliance was well discussed before the event, although the part played by overseas students to the Australian economy was a source of pride by governments and the university sector. As a leader in the Economist says (The absent student 2020) in relation to the effects of Covid19 "Yet the disaster may have an upside. For many years government subsidies and booming demand have allowed universities to resist changes that could benefit both students and society. They may not be able to do so for much longer... Universities 
are rightly proud of their centuries-old traditions, but their ancient pedigrees have too often been used as an excuse for resisting change. If covid-19 shakes them out of their complacency, some good may yet come from this disaster." The Institute of Fiscal Studies estimates that UK universities may face a loss of a quarter of their income in a year as a result of the pandemic (Drayton and Waltman 2020).

As mentioned in a previous section, the ethics of using fees from overseas students to support national educational institutions in their education and research activities is highly questionable.

A year or so before Covid-19, I wrote a short piece with my suggestions for future-proofing in case of a reduction in overseas student numbers-I could not find a publisher and now it is not a case of future-proofing but of dealing with a current as well as future over reliance on overseas students. I will take it as read that, in line with other sections in the book, there is a wish among nations to improve global access to quality higher education. But can we do this in an ethical way with benefits to both provider and recipient nations, and that resonates with other suggestions I am making for a sustainable future for higher education?

The goal is to continue to offer educational opportunities to students from less developed countries until they are able to build local capacity, maintain the benefits to trade and cultural exchange with current and future 'target' countries, and reduce the reliance and consequences for both parties on overseas student fees. I will use the Australian setting, with which I am most familiar, and in essence suggest that this will be a low cost approach using online education and volunteers from the 'third sector', while continuing to provide the opportunity for students to travel physically for their education - but in fewer numbers. My suggestions about cost saving to help with a reduction in student fee income are in another chapter, but the development of a sustainable overseas student arrangement will also have long-term financial benefit, even if at a lower level than currently.

I have talked about the 'Learning Ladder' where educational opportunities are to be provided across the lifespan when needed to support various career stages. This came from a paper that my colleagues and I published titled 'Building public health capacity through online global learning'. In our paper (Madhok et al. 2018) we defined online Global Learning as "innovative, integrated, global opportunities for capacity building through online learning and shared experiences between and within Low- to Middle-Income Countries and High-Income Countries, in a continuous process that helps health care workers learn as they progress through their careers". It is from this title that I borrow the name of the programme I am proposing here-'Global Online Learning'.

This will rely first on online learning, often termed e-learning, as the delivery mechanism with a major contribution from the Third Sector ('The Third Sector is constituted by all those organisations that are not-for-profit and non-government, together with the activities of volunteering and giving which sustain them.'). The relevant features of online learning include: a wide reach across geographies, gender, levels of income and employment; costs of travel and accommodation are avoided, and manpower is not depleted during education; environmental sustainability; no evidence that e-learning is less effective than face-to-face teaching; and access to 
a wide range of educational resources that are freely available on the web (Open Educational Resources), reducing costs of production.

The Third Sector is often ignored in educational thinking, although there are many examples of education offered by volunteer organisations, where volunteer tutors provide benefit to both tutors and students. I have described the value of volunteers in a previous section, and they will be a key feature of the programme proposed here.

Here are some details of the programme-which in Australia might be called 'Australia Online'.

- Goal: to go beyond the nation's current educational offerings for overseas students to create low cost online learning opportunities which will not only help with current educational needs but provide a bridge to future and extensive mutually beneficial educational partnerships between Australia and emerging economies.

- Benefits: a boost to boost Australia's credentials as a provider of international education, while immediately offering valuable educational opportunities in countries whose higher education systems are less well developed.

- Programme to be a collaboration between the Higher Education and the Third sectors

- Design features: fully online; ensure that programmes meet needs of low- to middle-income countries in terms of the knowledge and skills learned and the capacities to be built.

- Oversight: programme sited in the Third Sector with a core staff, but needs input from Low- to Middle-Income Countries, the Higher Education sector, and accreditation to ensure relevance and appropriate standards.

- Funding: shared between governments, philanthropists, students and donations. Higher Education sector to offer access to some courses, staff time and accreditation.

Such a programme will not solve the problem of global inequalities in access to higher education, nor the over dependence on overseas student fees. However, if it works, it could be expanded and serve as a good model.

Next is another proposed programme that could help break down barriers to education globally, and builds on the Open Educational Resources movement.

\subsection{Plan E for Education-Increasing Online Public Access to Higher Education}

Although universities have to generate some of their own finances, and in many countries students pay at least a portion of the costs of their education, public money subsidises higher education in most countries as a public good. The figure below from the OECD report 'Spending on tertiary education' (OECD 2021) shows the 


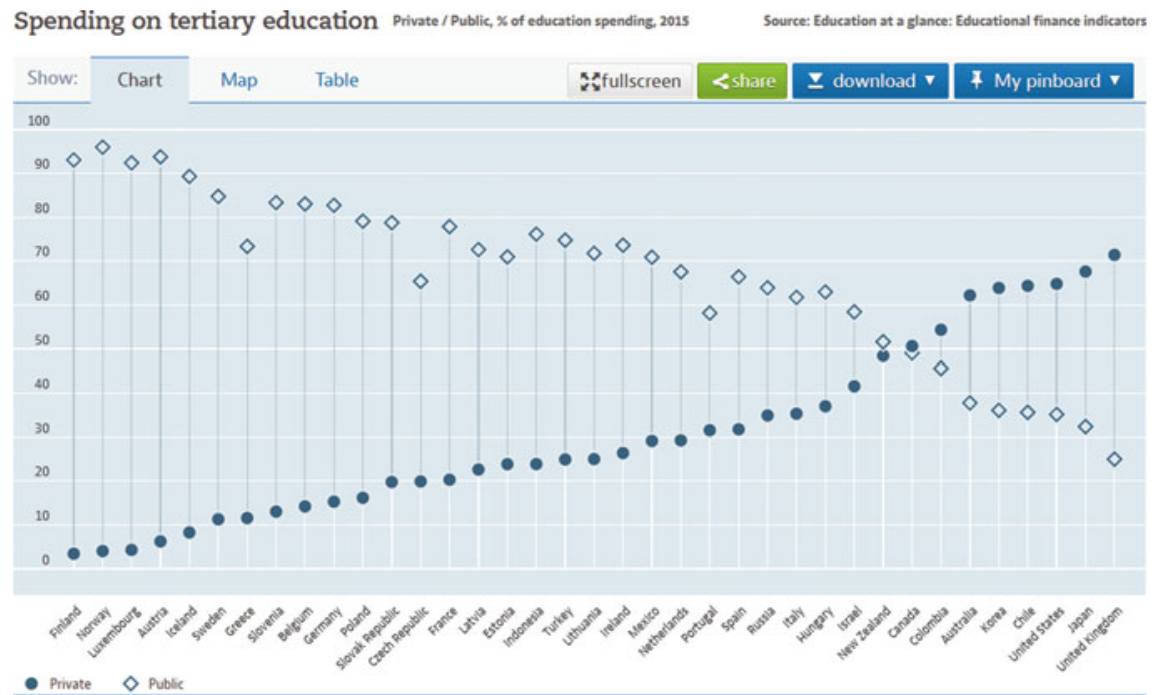

Fig. 3.4 Private/Public spending on tertiary education by country (OECD 2015)

variation among OECD countries, where in some countries the majority of funding is public money, and in others private funding contributes a larger proportion than from the public purse (Fig. 3.4).

The corporatisation of universities and the adoption of the competitive business model has resulted in higher education being sequestered behind massive 'paywalls'. Is it appropriate that public money should be spent on producing and delivering education that is not made freely available but is being used for competitive advantage by the universities that receive it? This discussion has been had over the years in relation to open publishing, and it is possible to use a Creative Commons licence https://creativecommons.org/ to publish your work so that it can be used by others (as in the case of this book). As discussed in the previous chapter on Open Educational Resources, a number of academic journals publish their articles using this kind of licence-and then the author, rather than the reader, has to pay the costs of producing and distributing the journal. I would like to offer a practical method to extend this concept from publication in journals and books, to educational materials produced by universities.

A good model on which to base this is Plan S, "an initiative for Open Access publishing that was launched in September 2018. The plan is supported by cOAlition $S$, an international consortium of research funders. Plan $S$ requires that, from 2021, scientific publications that result from research funded by public grants must be published in compliant Open Access journals or platforms" (https://www.coalitions.org/).

Although there have been some delays in the implementation of Plan S (https:// www.nature.com/articles/d41586-019-01717-2), there is widespread global support for the notion that publicly funded research should be freely available and not hidden 
behind paywalls. There are already many examples of publications of public importance being made freely available - many of the early publications relating to the Covid-19 pandemic have been published as open access for the public good.

This proposal is to create something similar for higher education-'Plan E for Education' through open online access.

There are many examples of open access for higher education, such as the Open Educational Resources (OER) and the Massive Open Online Course (MOOC) movements. I have discussed the UNESCO recommendations from 2019 which encourages Member States to consider "developing and implementing policies and/or regulatory frameworks which encourage that educational resources developed with public funds be openly licensed or dedicated to the public domain as appropriate, and allocating financial and human resources for the implementation and evaluation of policies" (https://unesdoc.unesco.org/ark:/48223/pf0000370936). But how is this 'encouragement' going to lead to implementation? What are the measurable goals or targets, what is the timetable, is there going to be oversight and by whom, and are there financial needs and if so how are these to be provided?

Creative Commons has also established an Open Education Platform, " a space for open education advocates and practitioners to identify, plan and coordinate multinational open education content, practices and policy activities" (https://network. creativecommons.org/cc-open-education-platform/), and this has generated interest from educators in 78 countries.

There are also examples of universities putting their materials online for anyone to access-with MIT an early leader in the field, launching the OpenCourseWare initiative in 2002 with 50 of their courses published freely online, now extending to all their courses (https://ocw.mit.edu/about/milestones/). In my professional area, the Johns Hopkins School of Public Health has a wonderful set of its courses freely available online to others. I have thought, maybe unfairly, that the reason for this was a kind of advertising-you can get the resources, but need to enrol to get academic credit. I am pretty sure that this is the business model of the MOOC initiative where universities have spent large amounts of money developing free courses. Despite the promise of MOOCs, they are not taking over the educational world or meeting global capacity building needs - they are mainly undertaken by those in high income countries and those who already have a higher degree.

While there are differences between, and within, countries in their funding models for education, in many countries such as the USA, Canada, UK and Australia the business model of universities includes the charging of fees to students in addition to government funding. Access to educational materials by most universities globally is restricted to those who enrol as students, and universities compete amongst themselves for these students. This competition is partly for funding and partly for reputational purposes, as the higher education sector transitions from its primary function of public education to becoming business enterprises. 
The idea behind Plan E is to question the rationale for educational resources, produced in whole or in part through government funding, playing into the competitive business model of the higher educational sector. Why are these publicly funded educational resources not be made freely available to those who might benefit?

There are examples of organisations who utilise open access educational materials making their higher education courses free or at low cost. These include Peoples-uni where volunteers translate available Open Educational Resources into programmes and courses for academic credit and continuing professional development (Heller et al. 2019a). These programmes aim to build capacity in low resource settings, where considerable benefit can be obtained by individuals and their communities through education which they would otherwise be unable to access.

Increasing access to high quality education materials produced by universities would allow their use both by individual autodidacts, as well as by organisations who would create other educational contexts for their use-such as Peoples-uni. Other organisations might also develop innovative delivery methods to contextualise open educational materials once such access was available. Thus high quality education, produced through public funding, can be democratised and spread where it is needed.

So Plan E would have three potential delivery strands—students access materials through the university that has produced them as per current practice, individual students could access materials for their own learning, and third party organisations can contextualise and deliver them in innovative ways.

In tandem with creating this access, we would suggest an accreditation system that would carry the accreditation afforded within the university who produced the material when it is offered outside the creating institution. This is more complex, but important for the originating university to be comfortable that the material is used appropriately. There could even be a staging post, where access is provided only to those who can provide an appropriate context for its use.

Asking myself the same questions that I used previously to criticise the UNESCO recommendation - the measurable goals or targets would be for all universities that receive public funding to make at least $10 \%$ of its offerings available online in this way within the next three years. The choice of materials would be up to the institution itself, but material of major global public interest should be prioritised. We would request that governments, state and national, as well as universities sign up to this. A philanthropic organisation would be identified to provide minimal infrastructure funding to allow an organisation, similar to cOALition S for science publication, to oversee the initiative, provide a repository or inventory of resources and consider accreditation. Could the Education Commission (https://educationcommission.org/ about/) take up this challenge?

Having exhausted my suggestions for solutions, I need to explain how they can be afforded. This next chapter shows how most of these ideas are actually cost saving, and could help universities survive as well as innovate. 


\section{References}

About the IB https://www.ibo.org/about-the-ib/

Alexander A, Manolchev C. The future of university or universities of the future: a paradox for uncertain times. Int J Educ Manag. 2020;34:1143-53. https://doi.org/10.1108/IJEM-01-20200018.

Annand D, Jensen T. Incentivizing the production and use of open educational resources in higher education institutions. IRRODL. 2017;18(4). https://doi.org/10.19173/irrodl.v18i4.3009

Barnett R. Learning for an unknown future. High Educ Res Dev. 2012;31(1):65-77. https://doi.org/ 10.1080/07294360.2012.642841.

Bijlsma-Frankema K, Costa AC. Understanding the trust-control Nexus. Int Sociol. 2005;20:25982. https://doi.org/10.1177/0268580905055477.

Brower HH, Lester SW, Korsgaard A. A closer look at trust between managers and subordinates: understanding the effects of both trusting and being trusted on subordinate outcomes. J Manag. 2008;35:327-47. https://doi.org/10.1177/0149206307312511.

CC Open Access Platform https://network.creativecommons.org/cc-open-education-platform/

Churches A. Bloom's digital taxonomy. 2008.

Computers \& Education: artificial intelligence https://www.journals.elsevier.com/computers-andeducation-artificial-intelligence/

Cook DA, Levinson AJ, Garside S, Dupras DM, Erwin PJ, Montori VM. Internet-based learning in the health professions: a meta-analysis. JAMA. 2008;300(10):1181-96. https://doi.org/10.1001/ jama.300.10.1181.

Das TK, Teng B-S. The risk-based view of trust: a conceptual framework. J Bus Psychol. 2004;19: 85-116. www.jstor.org/stable/25092888.

Dirks KT, Ferrin DL. The role of trust in organizational settings. Organ Sci. 2001;12:450-67. JSTOR. www.jstor.org/stable/3085982.

Drayton E, Waltman B. Will universities need a bailout to survive the COVID-19 crisis? Institute of fiscal studies. https://www.ifs.org.uk/publications/14919 (July 2020).

Dzimińska M, Fijałkowska J, Sułkowski Ł. Trust-based quality culture conceptual model for higher education institutions. Sustainability 2018;10:2599. https://doi.org/10.3390/su10082599.

Encyclopedia of educational philosophy and theory. Open Educational Practices (OEP) in higher education. July 2020. https://doi.org/10.1007/978-981-287-532-7_710-1.

Erickson M, Hanna P, Walker C. The UK higher education senior management survey: a statactivist response to managerialist governance. Stud High Educ. 2020.https://doi.org/10.1080/03075079. 2020.1712693.

European Commission. Education and training: International cooperation and policy dialogue. https://ec.europa.eu/education/policies/international-cooperation/international-cooper ation-and-policy-dialogue_en

Freidenfelds D, Kalnins SN, Gusca J. What does environmentally sustainable higher education institution mean? Energy Procedia. 2018;147:42-7.

Grimaldi PJ, Basu Mallick D, Waters AE, Baraniuk RG. Do open educational resources improve student learning? Implications of the access hypothesis. PLoS ONE. 2019;14(3):e0212508. https://doi.org/10.1371/journal.pone.0212508.

Guinot J, Chiva R. Vertical trust within organizations and performance: a systematic review. Hum Resour Manag Rev. 2019;18:196-227. https://doi.org/10.1177/1534484319842992.

Hastwell C. The business returns on a high-trust work culture. Great place to work. https://www. greatplacetowork.com/resources/blog/the-business-returns-on-high-trust-work-culture (2019).

Haymes T. Universitas Technologica: The Distributed University. Idea Spaces. https://ideaspaces. net/distributeduniversity/ (July 2018).

Heller R, Chilolo E, Elliott J, Johnson B, Lipman D, Ononeze V, Richards J. Do tutors make a difference in online learning? A comparative study in two open online courses. Open Praxis. 2019b;11:229-41. https://openpraxis.org/articles/10.5944/openpraxis.11.3.960/. 
Heller RF, Strobl J, Madhok R. Online education for public health capacity building in low- to middle-income countries: the peoples-uni experience. IRRODL 2019a;20(1). http://www.irrodl. org/index.php/irrodl/article/view/3927

Houldsworth A. Trust me I'm a Doctor; The importance of trust in promoting high performance learning in medical education. MedEdPublish 2020; 9:184.

Hyde MK, Dunn J, Scuffham PA, Chambers SK. A systematic review of episodic volunteering in public health and other contexts. BMC Public Health. 2014;14:992. https://doi.org/10.1186/ 1471-2458-14-992.

Jenkinson CE, Dickens AP, Jones K, et al. Is volunteering a public health intervention? A systematic review and meta-analysis of the health and survival of volunteers. BMC Public Health. 2013;13:773. https://doi.org/10.1186/1471-2458-13-773.

Joo J, Sleingo J, Alamuddin R. Unlocking the power of collaboration. How to develop a successful collaborative network in and around higher education. Analysis and Policy Observatory. https:// apo.org.au/node/264316 (Oct 2019).

Kezar A. Redesigning for collaboration within higher education institutions: an exploration into the developmental process. Res High Educ. 2005;46:831-60. https://doi.org/10.1007/s11162-004$6227-5$.

Kier CA. Plagiarism intervention using a game-based tutorial in an online distance education course. J Acad Ethics. 2019;17:429-39. https://doi.org/10.1007/s10805-019-09340-6.

KPMG. The future of higher education in a disruptive world. https://assets.kpmg/content/dam/ $\mathrm{kpmg} / \mathrm{xx} / \mathrm{pdf} / 2020 / 10 /$ future-of-higher-education.pdf (2020).

Laal M, Ghodsi SM. Benefits of collaborative learning. Procedia Soc Behav Sci. 2102;31:486-90

Madhok R, Frank E, Heller R. Building public health capacity through online global learning. Open Praxis. 2018;10:91-7. https://openpraxis.org/articles/10.5944/openpraxis.10.1.746/.

Making full and immediate Open Access a reality. https://www.coalition-s.org/

Mehling S, Kolleck N. Cross-sector collaboration in higher education institutions (HEIs): a critical analysis of an urban sustainability development program. Sustainability. 2019;11:4982. https:// doi.org/10.3390/su11184982.

Mintz S. Creating a more collaborative higher education ecosystem. Inside higher Ed. https://www. insidehighered.com/blogs/higher-ed-gamma/creating-more-collaborative-higher-education-eco system (Jan 2019).

MIT OpenCourseWare. Milestones. https://ocw.mit.edu/about/milestones/

Nascimbeni F, Burgos D, Spina E, Simonette MJ. Patterns for higher education international cooperation fostered by Open Educational Resources. Innovations Educ Teaching Int. 2020. https:// doi.org/10.1080/14703297.2020.1733045.

Nature News. Ambitious open-access Plan S delayed to let research community adapt. https://www. nature.com/articles/d41586-019-01717-2

Newell C, Bain A. Academics' perceptions of collaboration in higher education course design. High Educ Res Dev. 2020;39:748-63. https://doi.org/10.1080/07294360.2019.1690431.

Nichols G, Hogg E, Knight C, Storr R. Selling volunteering or developing volunteers? Approaches to promoting sports volunteering. Voluntary Sec Rev Int J Third Sec Res Policy Pract. 2019;10:3-18. https://doi.org/10.1332/204080519X15478200125132.

OECD. How international collaboration can help build the future of education. OECD 2017.

OECD. Spending on tertiary education. 2021 (data from 2015) https://data.oecd.org/eduresource/ spending-on-tertiary-education.htm

Open educational resources. UNESCO 2017. https://en.unesco.org/themes/ict-education/oer

Open Loop University http://www.stanford2025.com/open-loop-university

Penprase BE. The fourth industrial revolution and higher education. In: Gleason N. (eds) Higher education in the era of the fourth industrial revolution. Palgrave Macmillan, Singapore, 2018. https://doi.org/10.1007/978-981-13-0194-0_9.

People and planet. How sustainable is your university? https://peopleandplanet.org/universityleague 
Pilgrim C, Scanlon C. Don't assume online students are more likely to cheat. The evidence is murky. The Conversation. https://theconversation.com/dont-assume-online-students-are-more-likely-tocheat-the-evidence-is-murky-98936 (July 2018).

Rubin J. Collaborative Online International Learning (COIL). Internationalisation of Higher Education. 2017;2.

Scager K, Boonstra J, Peeters T, Vulperhorst J, Wiegant F. Collaborative learning in higher education: evoking positive interdependence. CBE Life Sci Educ. 2016;15:69. https://doi.org/10.1187/cbe. 16-07-0219.

Southby K, South J, Bagnall A. A rapid review of barriers to volunteering for potentially disadvantaged groups and implications for health inequalities. Voluntas. 2019;30:907-20. https://doi.org/ 10.1007/s11266-019-00119-2.

Sustainable development goal 17. https://sustainabledevelopment.un.org/sdg17

Tallant J, Donati D. Trust: from the philosophical to the commercial. Philos Manage. 2020;19:3-19. https://doi.org/10.1007/s40926-019-00107-y.

The absent student. Covid-19 will be painful for universities, but also bring change They need to rethink how and what they teach. The Economist. https://www.economist.com/leaders/2020/08/ 08/covid-19-will-be-painful-for-universities-but-also-bring-change (Aug 2020).

The Bologna process https://www.eua.eu/issues/10:bologna-process.html

The Education Commission. https://educationcommission.org/about/

The international commission on financing global education opportunity. The learning generationinvesting in education for a changing world. https://report.educationcommission.org/report/

U.S. Department of Education. Evaluation of Evidence-Based Practices in Online Learning: A Meta-Analysis and Review of Online Learning Studies. Washington, D.C.: Office of Planning, Evaluation, and Policy Development; 2009.

UN Environment program. Greening Universities Toolkit V2.0. https://www.unenvironment.org/ resources/toolkits-manuals-and-guides/greening-universities-toolkit-v20

UNESCO General Conference. Draft Recommendation on Open Educational Resources. UNESCO 2019. https://unesdoc.unesco.org/ark:/48223/pf0000370936

UNESCO recommendation on Open Educational Resources (OER). https://en.unesco.org/news/ unesco-recommendation-open-educational-resources-oer

van Niekerk P. The changing ethos of the university: living with supercomplexity. Acta Academia 2016;48:27-47. https://doi.org/10.18820/24150479/aa48i1.2.

What is open source? https://opensource.com/resources/what-open-source, https://Opensource.com

World Distributed University (WDU). https://www.newportuniversity.eu/global-education-system/ wdu/

World Economic Forum. Fourth Industrial Revolution. https://www.weforum.org/focus/fourth-ind ustrial-revolution

Open Access This chapter is licensed under the terms of the Creative Commons Attribution 4.0 International License (http://creativecommons.org/licenses/by/4.0/), which permits use, sharing, adaptation, distribution and reproduction in any medium or format, as long as you give appropriate credit to the original author(s) and the source, provide a link to the Creative Commons license and indicate if changes were made.

The images or other third party material in this chapter are included in the chapter's Creative Commons license, unless indicated otherwise in a credit line to the material. If material is not included in the chapter's Creative Commons license and your intended use is not permitted by statutory regulation or exceeds the permitted use, you will need to obtain permission directly from the copyright holder.

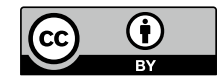

